Analysis of Premixed Charge

Compression Ignition Combustion with a Sequential Fluid Mechanics-Multizone Chemical Kinetics Model

S. M. Aceves, D. L. Flowers, F. Espinosa-Loza, A. Babajimopoulos, D. N. Assanis

October 1, 2004

2005 SAE World Congress

Detroit, MI, United States

April 11, 2005 through April 14, 2005 
This document was prepared as an account of work sponsored by an agency of the United States Government. Neither the United States Government nor the University of California nor any of their employees, makes any warranty, express or implied, or assumes any legal liability or responsibility for the accuracy, completeness, or usefulness of any information, apparatus, product, or process disclosed, or represents that its use would not infringe privately owned rights. Reference herein to any specific commercial product, process, or service by trade name, trademark, manufacturer, or otherwise, does not necessarily constitute or imply its endorsement, recommendation, or favoring by the United States Government or the University of California. The views and opinions of authors expressed herein do not necessarily state or reflect those of the United States Government or the University of California, and shall not be used for advertising or product endorsement purposes. 


\title{
Analysis of Premixed Charge Compression Ignition Combustion with a Sequential Fluid Mechanics-Multizone Chemical Kinetics Model
}

\author{
Salvador M. Aceves, Daniel L. Flowers Francisco Espinosa-Loza \\ Lawrence Livermore National Laboratory \\ Livermore, CA 94551
}

\author{
Aristotelis Babajimopoulos, Dennis N. Assanis \\ University of Michigan \\ Ann Arbor, MI 48109
}

\begin{abstract}
We have developed a methodology for analysis of PCCI engines that applies to conditions in which there is some stratification in the air-fuel distribution inside the cylinder at the time of combustion. Our analysis methodology consists of two stages: first, a fluid mechanics code is used to determine temperature and equivalence ratio distributions as a function of crank angle, assuming motored conditions. The distribution information is then used for grouping the mass in the cylinder into a two-dimensional (temperature-equivalence ratio) array of zones. The zone information is then handed on to a detailed chemical kinetics model that calculates combustion, emissions and engine efficiency information. The methodology applies to situations where chemistry and fluid mechanics are weakly linked. The results of the multi-zone model have been compared to the results obtained from a fully integrated code, in which a chemical kinetics code is directly linked into a fluid mechanics code to calculate chemistry in every cell of the grid.

The results show that the multi-zone model predicts burn duration and peak cylinder pressure with good accuracy. However, ignition timing predicted by the multi-zone model is sensitive to thetransition angle between the fluid mechanics code and the chemical kinetics code. The paper explores the possibility of using three different criteria for determining the transition angle: fraction of heat release at the time of ignition, temperature of the hottest cell at the time of ignition, and a fixed crank angle of transition. The results show that the three criteria have some validity as transition criteria. Further research is necessary to investigate the effect of fuel properties and operating conditions on transition angle.
\end{abstract}

\section{Introduction}

HCCI engines offer the promise of providing efficiency similar to diesel engines without the high $\mathrm{NO}_{\mathrm{x}}$ and particulate matter emissions that characterize diesel engine combustion. However, important challenges have kept HCCI engines from widespread 
commercialization. The main challenges are combustion timing control and low specific power output [1], with the control issue being especially difficult for transportation applications.

Premixed charge compression ignition (PCCI) is a possible solution to the control and specific power challenges of HCCI engines. PCCI is a generalization of HCCI combustion where the fuel and air mixture may be partially stratified at the moment of ignition. Examples of PCCI engines include direct injected engines with early injection [2], and controlled autoignition (CAI) engines that use variable valve timing and high residual fraction to control combustion [3]. In PCCI engines, equivalence ratio stratification may be used for lengthening the burn duration, thereby allowing the engine to operate at higher specific power. Engine control can also be aided by direct injection of fuel into the combustion chamber, especially if the injected fuel is highly reactive, such as diesel fuel. On the other hand, fuel stratification may produce high emissions of $\mathrm{NO}_{\mathrm{x}}$ and PM. The challenge for PCCI engines is to meet the control and high power output requirements of modern engines while keeping $\mathrm{NO}_{\mathrm{x}}$ and $\mathrm{PM}$ emissions low enough to meet current and future emissions standards.

Analysis of combustion in engines has always been extremely difficult. In theory, any engine combustion problem could be solved by linking a fluid mechanics code with a chemical kinetics code. In this fully integrated approach, the fluid mechanics code calculates temperature distribution and mixing, while the chemical kinetics code calculates composition and heat release. However, in SI and diesel engines, there are regions in the combustion chamber with very sharp gradients (i.e. flames) that require very fine meshes (micron-sized cells) for appropriate resolution. This makes the running time impractically long for today's computers.

HCCI combustion has unique characteristics that make it more amenable to analysis. It is widely believed that HCCI combustion is typically a distributed global auto-ignition phenomenon, with no sharp gradients such as flames. Turbulence is believed to play a minor role on HCCI combustion, affecting combustion only through its effect on the temperature distribution inside the cylinder. Under these conditions, accurate analysis of HCCI can potentially be achieved with a relatively coarse grid (millimeter-size cells instead of micron-size cells), with the cell size being determined by the need to appropriately resolve the temperature distribution in the cylinder. However, even the coarser grids required for HCCI combustion (with 50,000 cells for a 2-dimensional mesh or $\sim 500,000$ cells for a 3-dimensional mek) are too big for today's computers. Full integration of a fluid mechanics code with a chemical kinetics code may be the method of choice for HCCI analysis in the future, as fast, highly parallelized computers may be able to tackle the very high computational intensity of this problem. However, for now, fully integrated calculations are limited to small mechanisms ( 100 species) and coarse grids ( $\sim 1000$ cells). Recent work [4] has reported accurate results using this approach.

An alternative to full integration of a fluid mechanics code and a chemical kinetics code for HCCI analysis is to use a multi-zone model. In a multi-zone HCCI analysis, cells that have similar pressure, temperature and composition histories are grouped into a relatively 
small number of zones (10-100). The chemical kinetics solver is then applied to this small number of zones, instead of the large number of cells typically used in fluid mechanics codes. Considering that conducting chemical kinetics calculations is much more computationally expensive than conducting fluid mechanics calculations (Figure 1), it can be concluded that the multi-zone model can offer great advantage in computational time with respect to a full integration of a chemical kinetics code and a fluid mechanics code.

Previous work by the authors [5-6] has focused on developing and validating multi-zone models for HCCI combustion. The results have shown considerable success in predicting combustion and emissions over multiple geometries, fuels, and operating conditions. Previous applications of the multi-zone model have been limited to HCCI combustion, and the method does not allow for composition stratification inside the combustion chamber.

With the current interest in PCCI combustion and the previous success of the multi-zone model, it is tempting to try to extend the multi-zone model to PCCI combustion where partial composition stratification exists. While multi-zone methodologies are unlikely to work well in engines with substantial stratification or flame propagation (i.e., diesel and SI engines), they may work well enough under practical PCCI conditions to make them valuable analysis tools.

A multi-zone methodology that can be used for the analysis of PCCI combustion was previously proposed by two of the authors [7]. The method is a sequential multi-zone approach where the fluid mechanics code generates a temperature-equivalence ratio $(\mathrm{T}-\phi)$ distribution at a given transition point. The T- $\phi$ distribution is then used for generating a 2-dimensional array of zones, with zones having different compositions and temperatures. The zonal information is then passed on to a multi-zone chemical kinetic model that calculates combustion duration and heat release rates. The results in [7] showed that the model can predict burn duration and peak cylinder pressure with good accuracy. However a criterion for choosing the transition point was not clearly defined.

In this paper, this approach is further developed and evaluated. More specifically, the paper explores the possibility of using three different criteria for determining the transition angle: fraction of heat release at the time of ignition, temperature of the hottest cell at the time of ignition, and a fixed crank angle of transition. The next section describes the methodology in more detail. The method is later tested and the results are presented and discussed.

\section{The Model}

Figure 2 shows the main steps in the sequential multi zone methodology. The first step in the process is to conduct a fluid mechanics analysis of the engine cycle, assuming nonfiring (motored) conditions. The analysis may include the inlet and exhaust processes, as 
needed to analyze a CAI engine [3]. However, for this paper, we consider only the trapped cycle, from intake valve closing (IVC) to exhaust valve opening (EVO). The fluid mechanics code generates a list of temperatures and compositions for all the cells for multiple crank angles during the compression stroke. In this paper we use KIVA3V for the fluid mechanics calculations [8].

The second step in the process consists of selecting a crank angle for transitioning between the fluid mechanics code and the chemical kinetics code. The transition angle is an important parameter in the solution of the problem. Transitioning to the chemical kinetics code too early introduces errors, since mixing and heat transfer cannot be accurately modeled with the chemical kinetics code. Transitioning too late also introduces errors because the model may miss some of the early chemistry, which typically plays an important role in determining ignition timing. While there is no simple way to determine a priori the optimum transition angle, we analyze and present some possible criteria for selecting the transition angle. These preliminary criteria may later need to be modified or enhanced as further cases with different fuels and operating conditions are analyzed.

After the transition angle is selected, we process the information obtained from the fluid mechanics code and group the fluid mechanics cells into chemical kinetics zones. First, the number of zones is selected, as well as a mass distribution within the zones. In this paper we use 40 zones, consisting of 10 temperature zones, each of which is then subdivided into 4 equivalence ratio zones. The mass distribution of the zones is given in Table 1. These values were selected based on our previous experience in multi-zone models and then modified by trial and error.

Table 1. Temperature and equivalence ratio zoning distribution for multi-zone model.

\begin{tabular}{|c|c|c|c|c|c|c|c|c|c|c|}
\hline \multicolumn{11}{|c|}{ Temperature zones } \\
\hline $\begin{array}{l}\text { Zone }(1=\text { coldest, } \\
10=\text { hottest })\end{array}$ & 1 & 2 & 3 & 4 & 5 & 6 & 7 & 8 & 9 & 10 \\
\hline mass in zone, $\%$ & 2 & 2 & 2 & 5 & 7 & 10 & 12 & 15 & 20 & 25 \\
\hline \multicolumn{11}{|c|}{ Equivalence ratio zones } \\
\hline $\begin{array}{l}\text { Zone (1=leanest, } \\
4=\text { richest) }\end{array}$ & 1 & 2 & 3 & 4 & & & & & & \\
\hline $\begin{array}{l}\text { Mass fraction in } \\
\text { subzone, } \%\end{array}$ & 25 & 25 & 25 & 25 & & & & & & \\
\hline
\end{tabular}

Cells are then distributed among the 40 zones. Cells are first plotted in a temperatureequivalence ratio $(\mathrm{T}-\phi)$ chart and sorted according to temperature. Cells that correspond to the coldest $2 \%$ of the mass are assigned to temperature zone 1 , and the appropriate fractions of the total mass (from Table 1) are assigned to the following zones, until the hottest $25 \%$ of the mass is assigned to temperature zone 10 (Figure 2(c)). Each 
temperature zone is then divided into 4 equivalence ratio zones. In this paper we use a uniform equivalence ratio distribution, and therefore the mass in each temperature zone is equally divided between the four equivalence ratio zones, with the leanest cells going to zone 1 and the richest cells going to zone 4 .

Finally, the T- $\phi$ zoning information is fed into a chemical kinetics code. For this work, we use HCT (Hydrodynamics, Chemistry and Transport) [9]. HCT calculates pressure, temperature, combustion and chemical heat release as a function of crank angle from the transition angle to BDC (Figure 2(d)). HCT is run with a segregated solver that calculates the chemical kinetics of each zone separately, greatly reducing computational time [6]. The chemical kinetics run assumes that the zones interact through pressure equilibration only. No mixing or heat transfer between cells is considered. Heat transfer to the cylinder wall is calculated with the Woschni correlation [10].

\section{Model Validation}

Validating a PCCI model is more difficult than validating an HCCI model due to the complexity introduced by having an equivalence ratio distribution in addition to a temperature distribution. Differences between analytical and experimental results for PCCI combustion can then be due to deficiencies in the multi-zone model or due to deficiencies in the mixing and injection models used in the fluid mechanics codes. Since the purpose of this paper is to evaluate the multi-zone model, it is thought more appropriate to validate the model results against analytical results obtained from a fully integrated fluid mechanics-chemical kinetics code. As previously discussed, a fully integrated solution can yield very accurate results for HCCI combustion. While it is ultimately necessary to conduct a validation against experimental data, the comparison against the fully integrated results provides a good estimate of the accuracy of the sequential multi-zone methodology. Future work will focus on validating the model against experimental data for early direct injected and CAI engines.

For validation of the multi-zone model we have selected an idealized problem that is simple enough to be solved with a fully integrated fluid mechanics-chemical kinetics code. The grid used for the analysis is shown in Figure 2(a). This is an axisymmetric coarse grid with 2200 cells at intake valve closing. The chemical mechanism used in the analysis includes hydrocarbons up to $\mathrm{C}_{4}$ compounds, with a total of 179 species. The fuels selected for the analysis are methane and n-butane. N-butane is a chemically simple fuel that presents characteristics of practical fuels, such as early heat release. The octane number of $n$-butane is 92 . Other engine parameters and run conditions are listed in Table 2.

Table 2. Engine parameters and operating conditions used in the analysis.

\begin{tabular}{|l|l|}
\hline Parameter & Value \\
\hline Engine speed & $2007 \mathrm{rpm}$ \\
\hline
\end{tabular}




\begin{tabular}{|l|l|}
\hline Compression ratio & $10.5: 1$ \\
\hline Stroke & $13.5 \mathrm{~cm}$ \\
\hline Bore & $11.41 \mathrm{~cm}$ \\
\hline Connecting rod length & $21.6 \mathrm{~cm}$ \\
\hline Displacement & $1378 \mathrm{~cm}^{3}$ \\
\hline Crank angle at intake valve closing (IVC) & $-155^{\circ}$ \\
\hline Chemical kinetic mechanism & 179 species, up to $\mathrm{C}_{4}$ compounds \\
\hline Fuels & Methane, n-butane \\
\hline Pressure at IVC & 3.18 bar \\
\hline Temperature at IVC & $490 \mathrm{~K}$ for n-butane \\
& $573 \mathrm{~K}$ for methane \\
\hline Average equivalence ratio & 0.4 \\
\hline Residual gas fraction & $2 \%$ \\
\hline $\begin{array}{l}\text { Running time for a fully integrated solution on one } \\
\text { processor of a 2 GHz Linux computer }\end{array}$ & 1 week \\
\hline
\end{tabular}

For each of the two fuels being analyzed in the idealized problem, we consider four initial equivalence ratio distributions (at IVC). The purpose of these four distributions is to analyze the effect of different levels of stratification on PCCI combustion. Distributions are titled steep, shallow, homogeneous and reverse (Figure 3). It is assumed that the initial equivalence ratio distribution is only a function of the cylinder radius and not a function of the axial position along the cylinder. All the distributions have the same average equivalence ratio $(0.4)$.

In total, we analyze 8 cases ( 2 fuels and 4 initial equivalence ratio distributions for each fuel). For each of these cases, we have calculated a fully integrated solution, as well as multiple solutions from the multi-zone model, obtained for different transition angles between the fluid mechanics and the chemical kinetics calculations. The following section describes the fully integrated results and the multi-zone results.

\section{Results}

Figures 4-8 show the evolution of the T- $\phi$ distribution as a function of crank angle, for the steep case with $n$-butane fuel. The figures show equivalence ratio and temperature for all the cells. The size of the symbols in the figures is proportional to the mass located in each of the cells. Initially, at IVC $\left(-155^{\circ}\right)$, all cells have the same temperature and a very broad equivalence ratio distribution. As the mixture is compressed, the average temperature increases and some temperature stratification appears due to heat transfer to the walls. Small cells (located at the boundaries, see Figure 2 (a)) are typically colder than the bigger, core cells. The figures also show that the equivalence ratio range shrinks as the mixture is compressed, due to mixing between rich and lean cells. At- $20^{\circ}$ the distribution only extends from 0.3 to 0.6 in equivalence ratio, compared to the broader initial distribution. At $20^{\circ}$ all the symbols in the figure are of similar size, indicating that all the cells have approximately the same mass. This is because the big cells that exist in 
the mesh at IVC (Figure 2(a)) have disappeared as TDC is approached due to compression of the mesh. Near TDC all the cells are of similar size.

Figure 2(c) shows the T- $\phi$ distribution at $-16^{\circ}$ for the steep case with n-butane. In addition to showing the $\mathrm{T}-\phi$ distribution, the figure shows how the cells are grouped into temperature zones, according to the zoning distribution detailed in Table 1. The temperature zones are then each divided into four equivalence ratio zones (not shown in Figure 2(c)), with each $\phi$ zone holding a fourth of the mass in the temperature zone.

The results of the fully integrated fluid mechanics-chemical kinetics calculations are shown in Figure 9. This figure shows pressure as a function of crank angle for the four initial equivalence ratio distributions (steep, shallow, homogeneous and reverse, see Figure 3), for both n-butane and methane. The figure shows that the steep case always burns first, followed by the shallow, uniform and finally the reverse. This is a consequence of the thermodynamic properties of the air-fuel mixtures: leaner mixtures have a higher specific heat ratio $\left(\gamma=c_{p} / c_{v}\right)$ than rich mixtures, and therefore heat up faster during compression. As Figure 3 indicates, the steep case has a leaner mixture at the center, and therefore ends up with a hotter core at the end of the compression stroke, resulting in earlier ignition. As we move from the steep case into the shallow, homogeneous and steep cases, the equivalence ratio at the center increases, and the core does not heat up as much during compression, resulting in later ignition.

Figure 9 also shows thatequivalence ratio stratification has little effect on burn duration, at least for the conditions analyzed in this paper. More equivalence ratio stratification may be necessary to cause a major change on burn duration, although care has to be taken that the broader distribution in equivalence ratio does not result in considerably higher $\mathrm{NO}_{\mathrm{x}}$ emissions.

Figure 2(d) shows a comparison between the pressure trace calculated from the fully integrated code and five pressure traces calculated from the multi-zone model, for the steep case with n-butane. The pressure traces calculated from the multi-zone model are obtained for five different transition angles between the fluid mechanics solution and the chemical kinetics solution $\left(-20^{\circ},-18^{\circ},-16^{\circ},-14^{\circ}\right.$ and $-12^{\circ}$, see method description above). The figure shows that the multi-zone solutionsaccurately predict peak cylinder pressure and burn duration, and the solution for $-16^{\circ}$ yields a very good approximation to the pressure trace calculated from the fully integrated method. However, the results of the multi-zone model are sensitive to the transition angle. Delaying the transition between the fluid mechanics code and the chemical kinetics code by $2^{\circ}$ delays the ignition timing by approximately $1^{\circ}$.

From Figure 2(d) it is possible to calculate (by interpolation) the transition angle that yields an exact prediction of the ignition timing. This optimum transition angle is $-16.5^{\circ}$. We can then conduct a similar calculation for the remaining 7 cases ( 3 for butane and 4 for methane) by interpolating from pressure trace figures similar to Figure 2(d) (these figures are not shown in this paper). The results are shown in Figure 10. This figure shows the optimum transition angle that can be used for matching the ignition timing, for 
methane and n-butane, for the four fuel-air distributions. The figure shows that the optimum transition angle changes little for all the cases presented. The optimum transition angle varies within a range of $2^{\circ}$, between $-16.5^{\circ}$ and $-14.5^{\circ}$, for the 8 cases being analyzed. Considering that changing the transition angle by $2^{\circ}$ changes the ignition timing by approximately $1^{\circ}$ (see Figure $2(\mathrm{~d})$ ), it can be concluded that using the average optimum transition angle $\left(-15.5^{\circ}\right)$ is likely to predict ignition timing with a maximum error of about $0.5^{\circ}$ for the steep and reverse distributions, and it would likely yield very accurate ignition predictions for the shallow and homogeneous cases.

Figure 11 shows a comparison between fully integrated and multi-zone solutions for nbutane, for the four equivalence ratio distributions being considered. All the multi-zone solutions consider $-16^{\circ}$ as the transition angle between the fluid mechanics and the chemical kinetic solution. This transition angle is chosen because it is the closest to the average optimum transition angle $\left(-15.5^{\circ}\right)$, considering that multi-zone runs were conducted at $2^{\circ}$ intervals between $-20^{\circ}$ and $-12^{\circ}$. The multi-zone method with transition at $-16^{\circ}$ predicts well the pressure traces, especially for the early combustion cases. For the reverse case, the agreement between the fully integrated solution and the multi-zone solution is not as good, as this case has a late optimum transition angle $\left(-14.5^{\circ}\right)$.

The comparison between multi-zone and fully integrated pressure traces for methane is shown in Figure 12. The results are once again shown for transitioning between the fluid mechanics and the chemical kinetic solution at $-16^{\circ}$. The results are similar to those of Figure 11, showing good agreement between fully integrated and multi-zone solutions for the early combustion cases. For the reverse case, the multi-zone model predicts an early ignition timing compared to the fully integrated solution. Once again, this is because the reverse case has the latest transition angle, and could be better matched with the run made for transition at $-14^{\circ}$.

\section{The Transition Angle}

The multi-zone model described here yields good predictions of pressure traces and burn duration, but the ignition timing is sensitive to the transition angle between the fluid mechanics code and the chemical kinetics code. The model is useful for PCCI engine analysis even without a universal transition criterion, as the model can predict heat release rate with good accuracy, and combustion timing is often known (optimum combustion timing is typically a few degrees after TDC). However, it is still desirable to define a criterion that can be used to decide when transition should occur.

For the 8 cases considered in this paper, it is apparent that a very simple transition criterion can be used for accurately predicting ignition: $\theta=-15.5^{\circ}$. As previously discussed, this transition angle predicts ignition timing with a maximum error of $0.5^{\circ}$. While this is a simple criterion to use and follow, it may have to be adjusted as different fuels and different engine geometries are considered. In addition to this, it is desirable to adopt a physics based criterion that may achieve greater generality. 
As previously discussed, the optimum transition angle is determined by a balance between the error associated with ignoring the early chemistry and the error associated with inaccurately calculating mixing and heat transfer in the multi-zone model. Transitioning to the chemical kinetics code too early introduces errors, since mixing and heat transfer cannot be accurately modeled with the chemical kinetics code. Transitioning too late also introduces errors because the model may miss some of the early chemistry, which typically plays an important role in determining ignition timing. Based on this, we consider the possibility of using chemicalheat release or the temperature of the hottest cell in the cylinder as indicators of transition angle.

Figures 13 and 14 show cumulative chemical heat release, expressed as a fraction of the total available chemical heat release (in logarithmic scale) as a function of crank angle, for the four fuel-air distributions. Figure 13 shows results for n-butane and Figure 14 for methane. Chemical heat release in these figures is calculated from the fully integrated solution. The figures also include four points that indicate the transition angle that best predicts ignition for the multi-zone model (from Figure 10).

Figure 13 shows that the points that indicate the optimum transition angles for n-butane are clustered at approximately $3 \times 10^{-4}$ heat release fraction. For methane (Figure 14), the optimum transition points span a wider range of heat release fraction, between $10^{-5}$ and $5 \times 10^{-5}$. From these figures it is apparent that it may be possible to use fraction of heat release as a criterion for determining transition angle. However, different criteria need to be used for different fuels (and possibly also for different operating conditions). The greater spread of the results for methane compared to n-butane may be due to the lower chemical reactivity of methane at low temperatures. For methane, early heat release has a relatively weak effect on ignition timing.

A difficulty with using chemical heat release as a criterion for transition is the fact that the multi-zone model does not calculate heat release before transition (the fluid mechanics code is run assuming motored conditions). Therefore, setting a transition criterion based on early heat release would require that heat release be calculated by a different methodology. Ideally, this would be a simplified methodology that is easy to implement and not computationally intensive. An artificial neural network [11] may be ideal for this application.

We have also explored the possibility of using the temperature of the hottest cell as a transition criterion. The rationale for this is that the hottest cell is responsible for ignition, and the temperature of the hottest cell is an indication of how far the charge is from ignition. The results are shown in Figures 15 and 16. These figures show the temperature of the hottest cell as a function of crank angle, for the four fuel-air distributions. The temperature distributions are obtained from the fully integrated runs. However, the motored temperatures are nearly identical to the fully integrated temperatures, because there is very little heat release at the time of transition (see Figures 13 and 14). Figure 15 shows the results for n-butane and Figure 16 for methane. The figures also include four 
points that indicate the transition angle that best predicts ignition for the multi-zone model (from Figure 10).

Figures 15 and 16 show that it may be possible to use the temperature of the hottest cell to predict transition angle, as these temperatures do not change much for the four fuel-air distributions. However, once again, it may be necessary to set a different transition criterion for different fuels, as the temperature is different for the two fuels being considered. As may be expected, the temperature for methane at the time of transition is approximately $100 \mathrm{~K}$ higher than the temperature for n-butane. Once again, this is due to the lower reactivity of methane at low temperatures.

Finally, it is important to determine why the ignition timing is so sensitive to the transition angle. If the main reason for the sensitivity is the inaccuracy of the heat transfer correlation, it may be possible to "tune" the heat transfer correlation to reduce the sensitivity. Recent research [12] has focused on improving the applicability of the heat transfer correlation for HCCI combustion. It may be possible to use the correlations derived in [12] to reduce the effect of the transition angle on ignition.

\section{Cnclusions}

We have developed a methodology for analysis of premixed charge compression ignition (PCCI) engines that applies to conditions in which there is some stratification in the airfuel distribution inside the cylinder at the time of combustion. Our analysis methodology consists of two stages: first, a fluid mechanics code is used to determine temperature and equivalence ratio distributions as a function of crank angle, assuming motored conditions. The distribution information is then used for grouping the mass in the cylinder into a twodimensional (temperature-equivalence ratio) array of zones. The zone information is then handed on to a detailed chemical kinetics model that calculates combustion, emissions and engine efficiency information. The methodology applies only to situations where chemistry and fluid mechanics are weakly linked. The results of the multi-zone model have been compared to the results obtained from a fully integrated code, in which a chemical kinetics code is directly linked into a fluid mechanics code to calculate chemistry in every cell of the grid. The main conclusions from the analysis are listed next.

1. The multi-zone model predicts burn duration and peak cylinder pressure with good accuracy.

2. The ignition timing predicted by the multi-zone model is sensitive to the transition angle between the fluid mechanics code and the chemical kinetics code.

3. It is desirable to establish a criterion to determine the transition angle. In this paper we attempted the following possibilities:

a. The simplest criterion appears to be to transition at $-15.5^{\circ}$. This very simple criterion worked well, predicting ignition within $\pm 0.5^{\circ}$ for the 8 cases being considered in this paper. 
b. Chemical heat release at the transition angle may be a good criterion, as it is an indication of how much of the early chemistry is being neglected by the multi-zone model. This criterion worked reasonably well. However, a different criterion needs to be established foreach of the two fuels considered here.

c. Temperature of the hottest cell may also be a good criterion, since this temperature is an indication of how far the charge is from ignition. Again, the criterion appears to work reasonably well, although a different criterion needs to be applied for the two different fuels.

4. The model has applicability even without a universal transition criterion, as the model predicts heat release rates with good accuracy, and the ignition timing is often known a priori. However, it is desirable to conduct further research to evaluate the generality of the criteria described here for transition between the fluid mechanics code and the heat transfer code. Ultimately it is necessary to compare the merits of this methodology with alternative methodologies for analyzing PCCI combustion [13-14].

\section{Acknowledgments}

This project is funded by DOE, Office of FreedomCAR and Vehicle Technologies, Gurpreet Singh and Steve Goguen, program managers. Work performed under the auspices of the U.S. Department of Energy by University of California, Lawrence Livermore National Laboratory under Contract W-7405-ENG-48.

\section{References}

1. Epping, K., Aceves, S.M., Bechtold, R.L., and Dec, J.E., 2002, “The Potential of HCCI Combustion for High Efficiency and Low Emissions," SAE Paper 200201-1923.

2. Miyamoto, T., Hayashi, A. K., Harada, A., Sasaki, S., Hisashi, A., and Tujimura, K., "A Computational Investigation of Premixed Lean Diesel Combustion," SAE paper 1999-01-0229, 1999.

3. Zhao, H., Peng, Z., Williams, J., Ladommatos, N., "Understanding the Effects of Recycled Burnt Gases on the Controlled Autoignition (Cai) Combustion in FourStroke Gasoline Engines," SAE paper 2001-01-3607, 2001.

4. Kong, S.C., Reitz, R.D., Christensen, M., Johansson, B., "Modeling the Effects of Geometry-Generated Turbulence on HCCI Engine Combustion," SAE Paper 2003-01-1088, 2003.

5. Aceves, S. M., Flowers, D. L., Martinez-Frias, M., Dibble, R., Wright, J. F., Akinyemi, W. C., and Hessel, R. P., "A Sequential Fluid-Mechanic ChemicalKinetic Model of Propane HCCI Combustion," SAE Paper 2001-01-1027, 2001.

6. Aceves, S.M., Martinez-Frias, J., Flowers, D.L., Smith, Dibble, R.W., Wright, J.F., and Hessel, R.P., "A Decoupled Model of Detailed Fluid Mechanics 
Followed by Detailed Chemical Kinetics for Prediction of Iso-Octane HCCI Combustion," SAE Paper 2001-01-3612, 2001.

7. Babajimopoulos, A., Lavoie, G.A., Assanis, D.N., "Modeling HCCI Combustion with High Levels of Residual Gas Fraction - A Comparison of Two VVA Strategies," SAE Paper 2003-01-3220, 2003.

8. Amsden, A.A., "KIVA-3: A KIVA Program with Block-Structured Mesh for Complex Geometries," Los Alamos National Laboratory Report LA-12503-MS, 1993.

9. Lund, C. M., "HCT - A General Computer Program for Calculating TimeDependent Phenomena Involving One-Dimensional Hydrodynamics, Transport, and Detailed Chemical Kinetics," Lawrence Livermore National Laboratory report UCRL-52504, 1978.

10. Woschni, G., "Universally Applicable Equation for the Instantaneous Heat Transfer Coefficient in the Internal Combustion Engine," SAE Paper 670931, 1967.

11. Choi, Y., and Chen, J.-Y., "Numerical Modeling of Start-Of-Combustion (SOC) in HCCI Engine with Artificial Neural Network (ANN)," Paper Number WSS/CI 03F-69, Proceedings of the 2003 Western States Meeting of the Combustion Institute.

12. Filipi, Z.S., Chang, J., Guralp, O.A., Assanis, D.N., Kuo, T.W., Najt, P.M., Rask, R.B., "New Heat Transfer Correlation for the HCCI Engine Derived from Measurements of Instantaneous Surface Heat Flux," SAE Paper 2004-01-2996.

13. Babajimopoulos, A., Flowers, D.L., Aceves, S.M., Hessel, R. P., and Assanis, D.N., "A Fully Integrated CFD and Multi-zone Model with Detailed Chemical Kinetics for the Simulation of PCCI Engines," Submitted to the International Journal of Engine Research, 2005.

14. Hessel, R.P., Flowers, D.L., Aceves, S.M., "Estimating Combustion with CFD and Detailed Chemistry using an Equivalence Ratio-Temperature Multi-Zone Methodology," Submitted to the SAE Congress, 2005. 


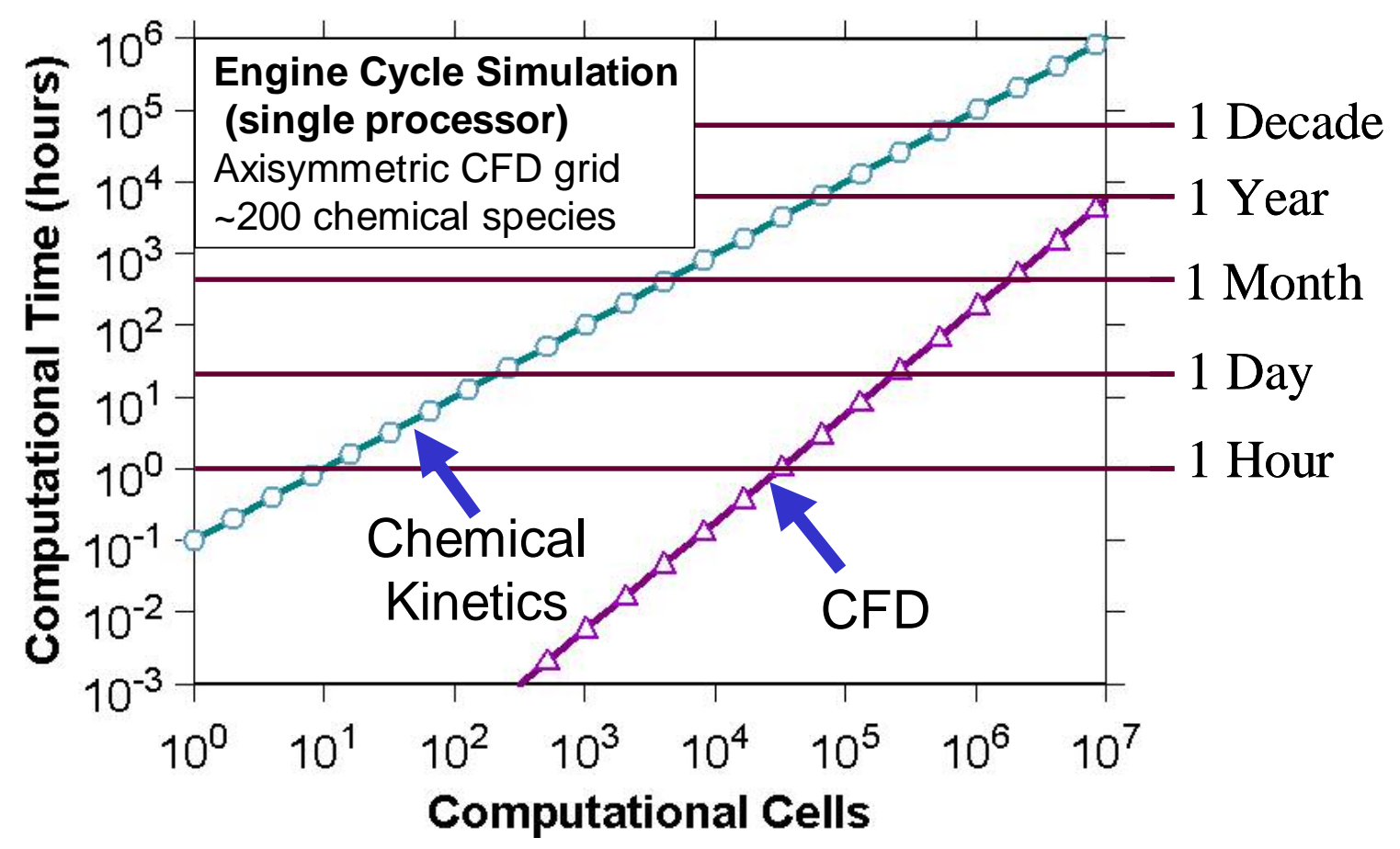

Figure 1. Computational time in a single processor of a LINUX computer as a function of the number of computational cells for a computational fluid mechanics (CFD) calculation and a chemical kinetics calculation. 
(a)

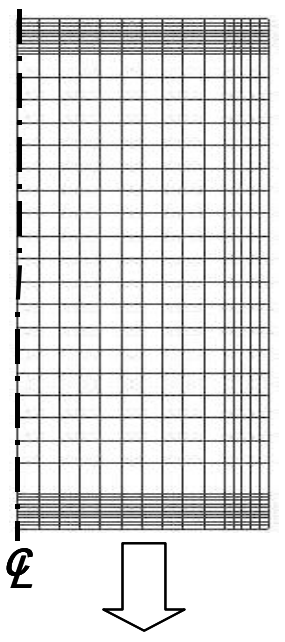

\section{Select transition time}

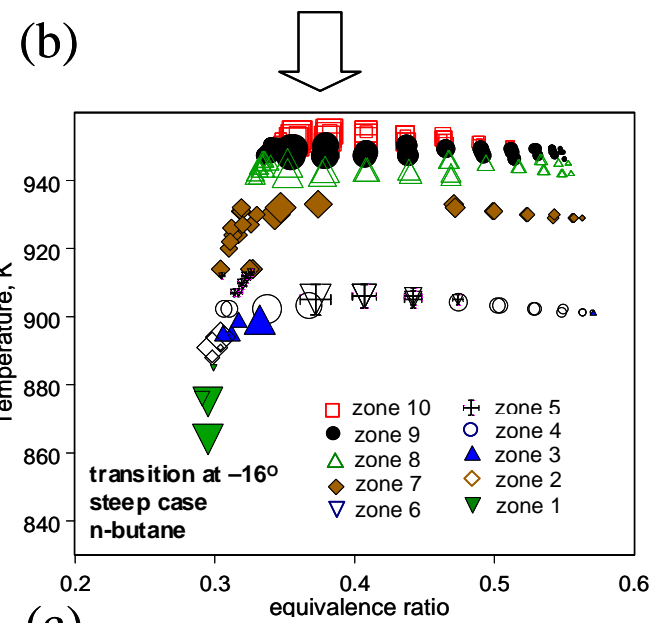

(c)
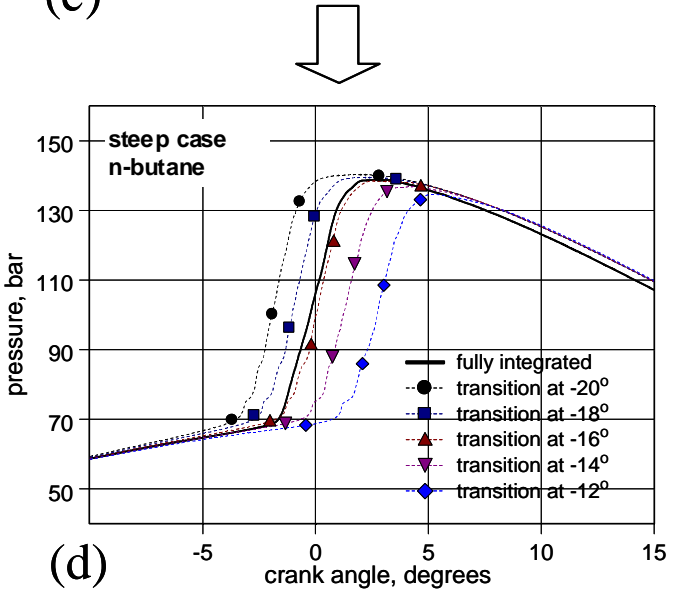

Figure 2. Sequence of calculations for the multi-zone methodology. (a) Conduct a fluid mechanics analysis of the engine cycle, assuming non-firing (motored) conditions. (b) Select a crank angle for transitioning between the fluid mechanics code and the chemical kinetics code. (c) Group fluid mechanics cells into chemical kinetics zones. (d) Run chemical kinetics code to calculate firing conditions. 


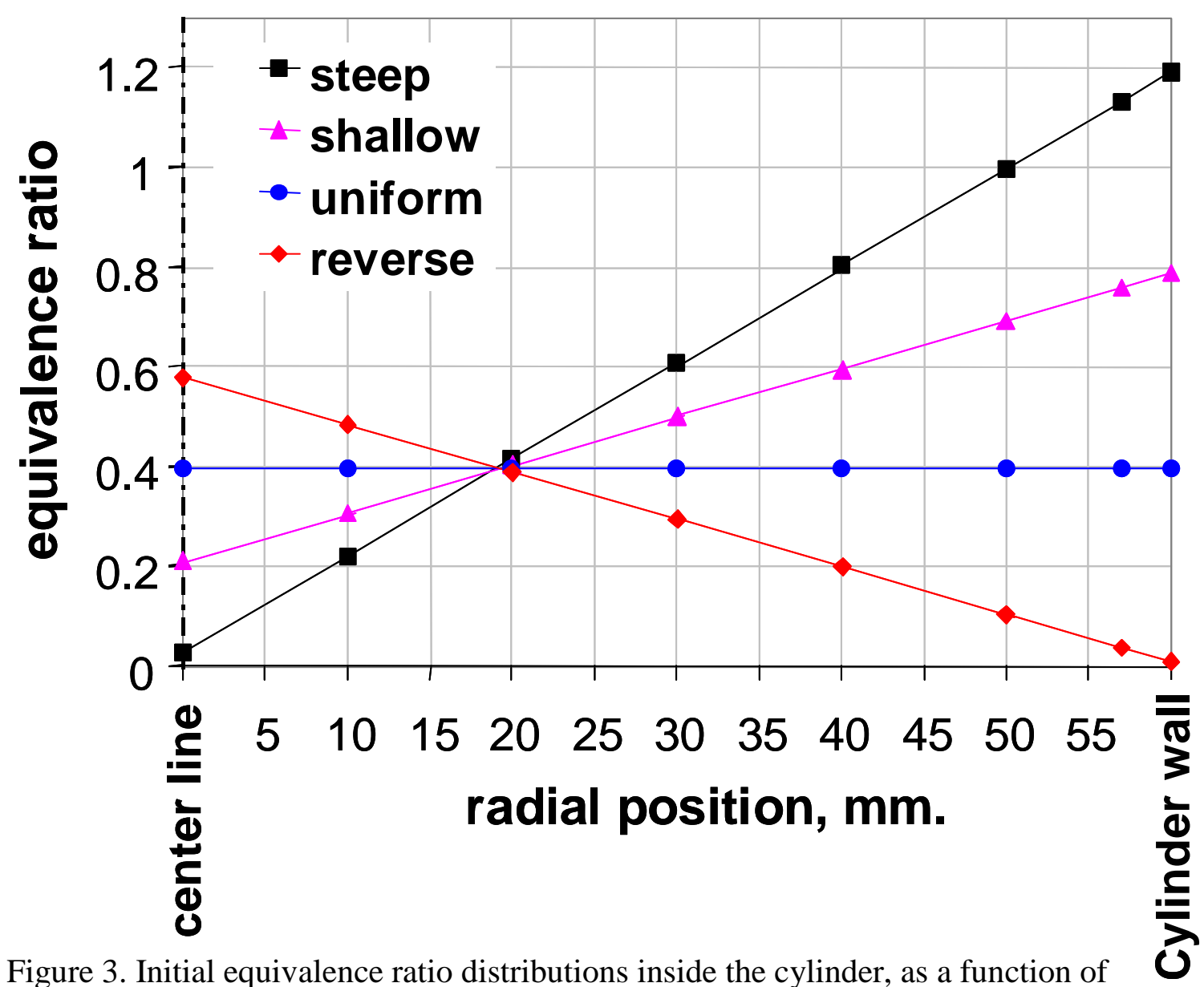

cylinder radius, at intake valve closing, for four different distributions, titled steep, shallow, homogeneous and reverse. The initial equivalence ratio distribution is only a function of the cylinder radius and not a function of the axial position along the cylinder. 


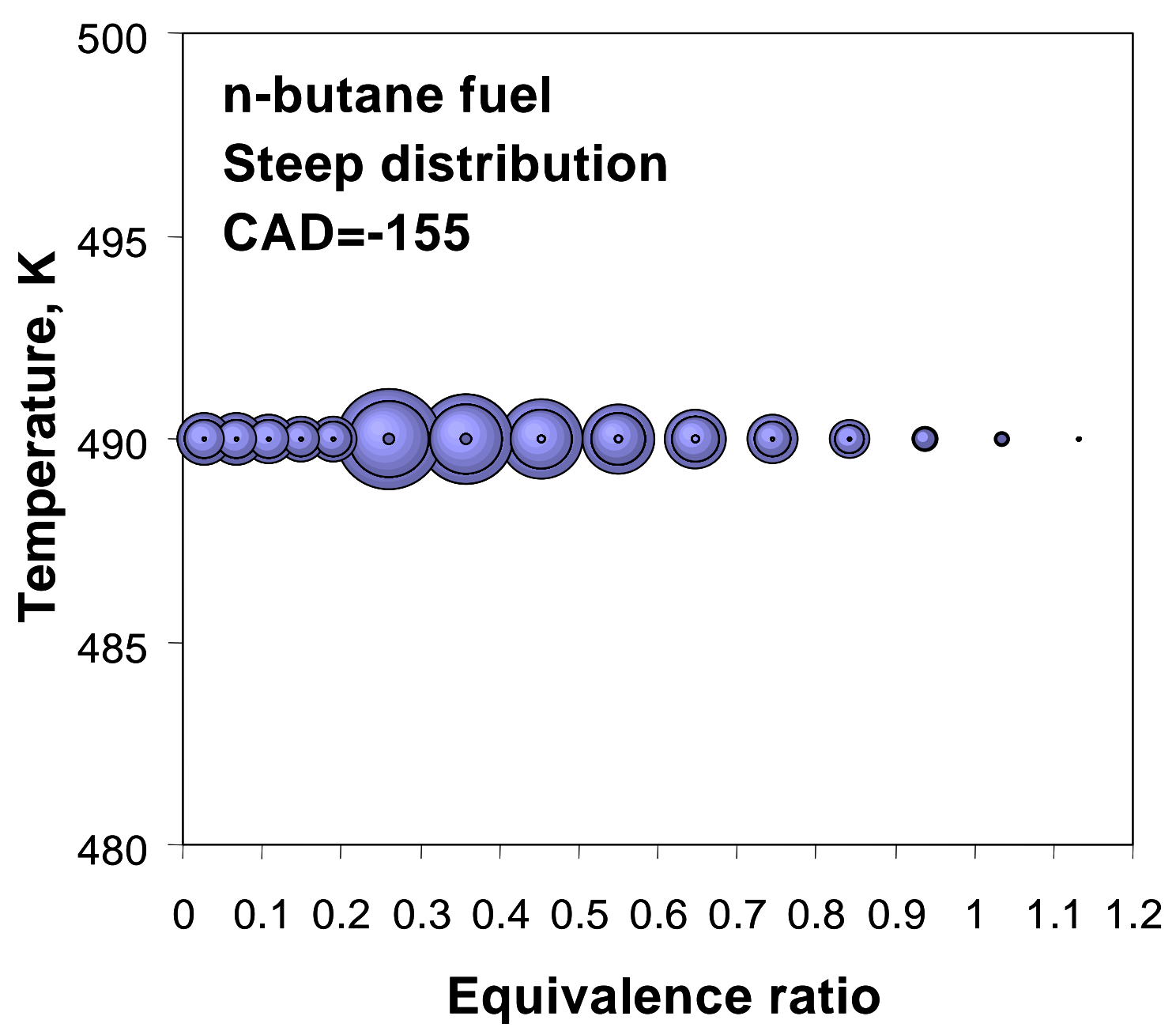

Figure 4. Temperature-equivalence ratio $(\mathrm{T}-\phi)$ distribution at $-155^{\circ}$ crank angle for the steep case with n-butane fuel. The figure shows equivalence ratio and temperature for all the cells in the fluid mechanics mesh. The size of the symbols in the figure is proportional to the mass located in each of the cells. 


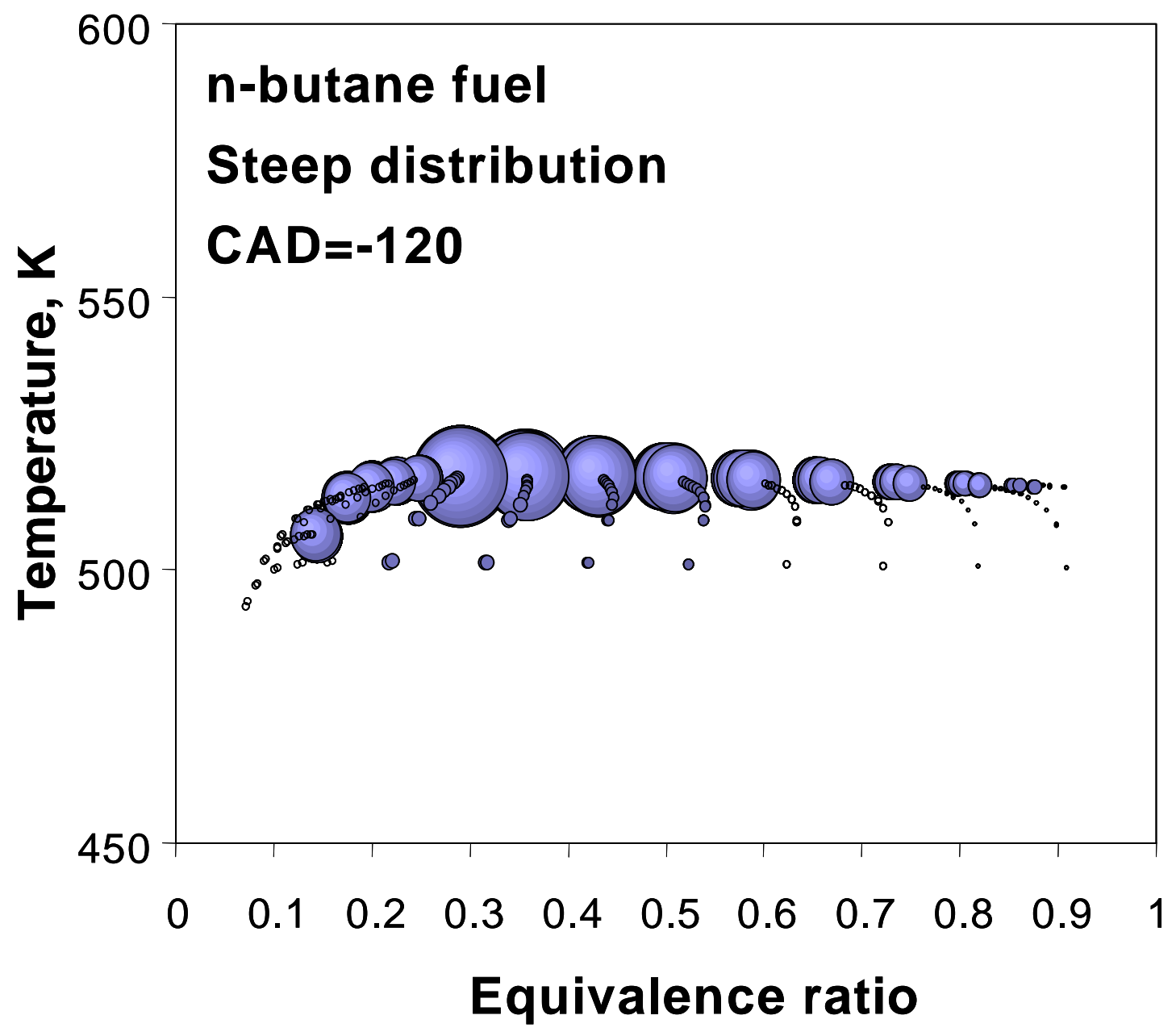

Figure 5. Temperature-equivalence ratio $(\mathrm{T}-\phi)$ distribution at $-120^{\circ}$ crank angle for the steep case with n-butane fuel. The figure shows equivalence ratio and temperature for all the cells in the fluid mechanics mesh. The size of the symbols in the figure is proportional to the mass located in each of the cells. 


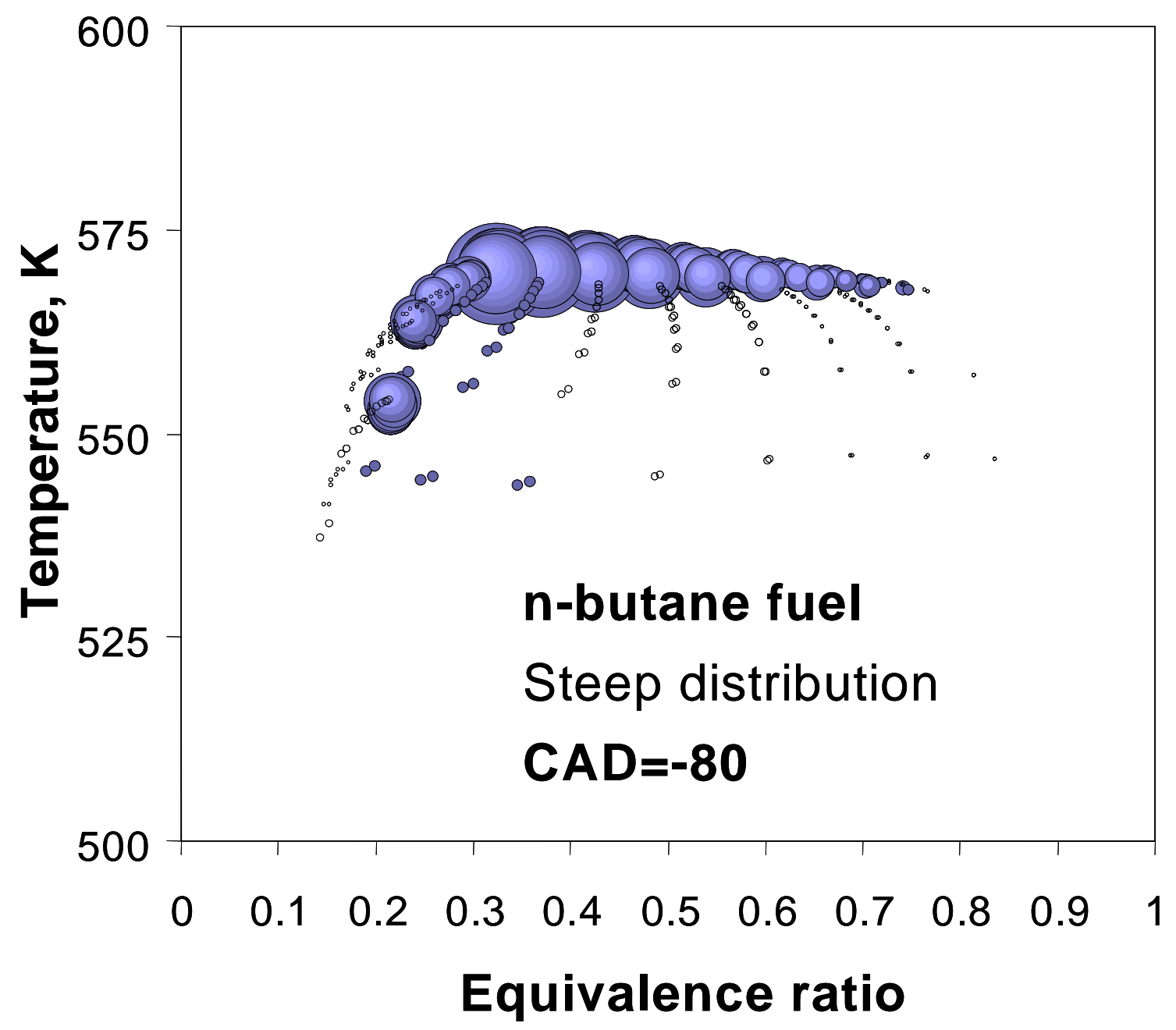

Figure 6. Temperature-equivalence ratio $(\mathrm{T}-\phi)$ distribution at $-80^{\circ}$ crank angle for the steep case with n-butane fuel. The figure shows equivalence ratio and temperature for all the cells in the fluid mechanics mesh. The size of the symbols in the figure is proportional to the mass located in each of the cells. 


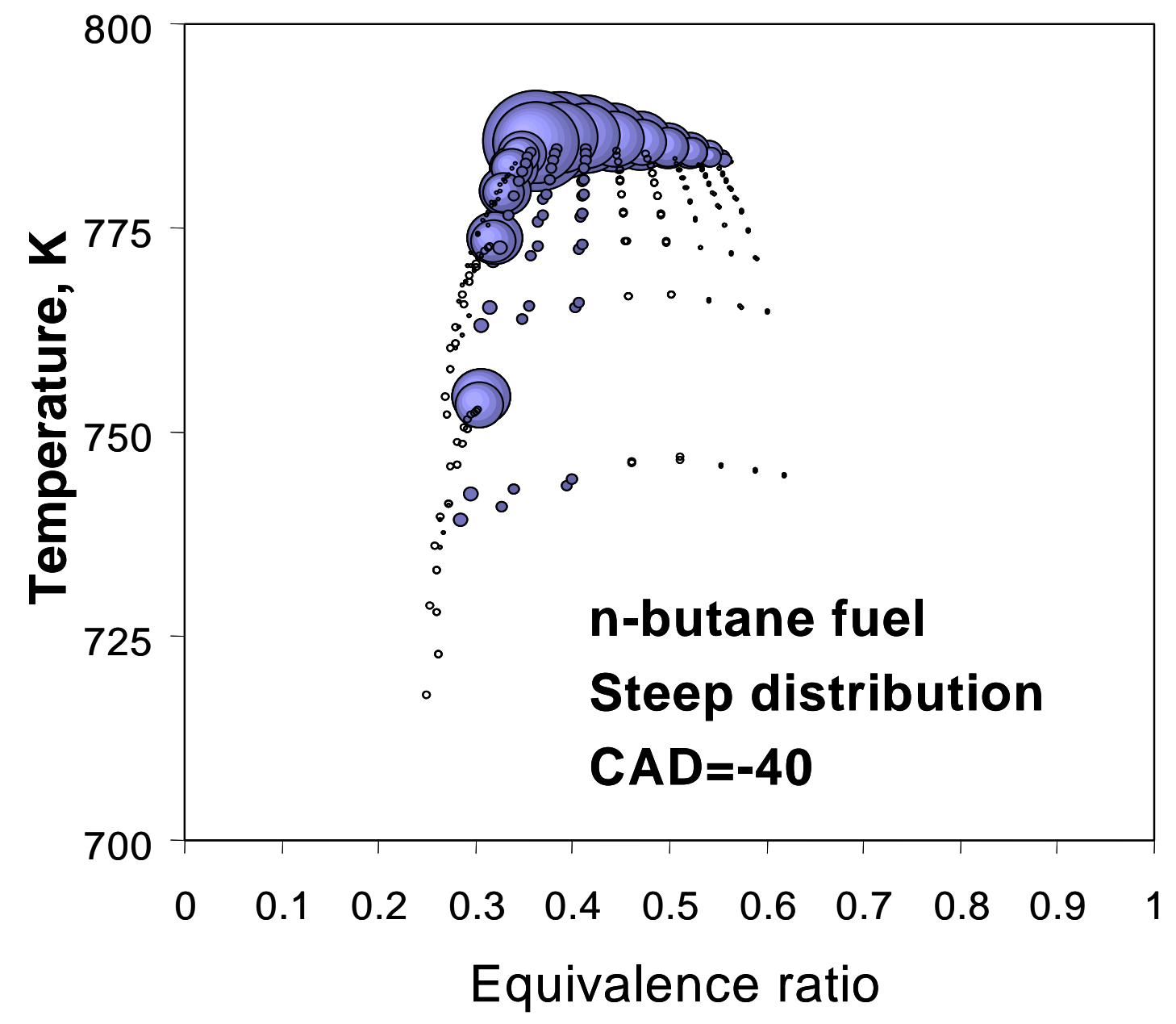

Figure 7. Temperature-equivalence ratio (T- $\phi)$ distribution at $-40^{\circ}$ crank angle for the steep case with $\mathrm{n}$-butane fuel. The figure shows equivalence ratio and temperature for all the cells in the fluid mechanics mesh. The size of the symbols in the figure is proportional to the mass located in each of the cells. 


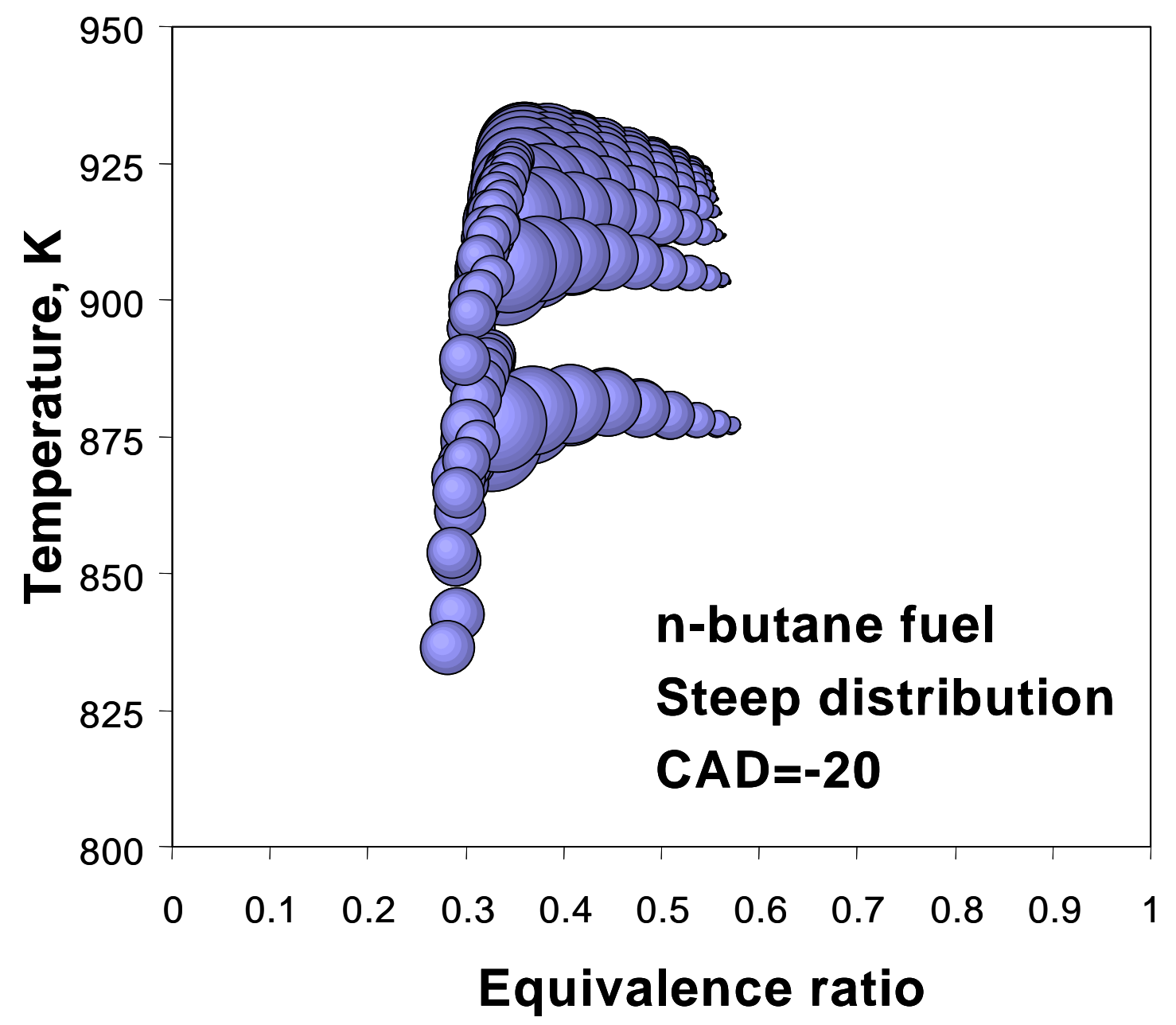

Figure 8. Temperature-equivalence ratio (T- $\phi$ ) distribution at $-20^{\circ}$ crank angle for the steep case with $\mathrm{n}$-butane fuel. The figure shows equivalence ratio and temperature for all the cells in the fluid mechanics mesh. The size of the symbols in the figure is proportional to the mass located in each of the cells. 


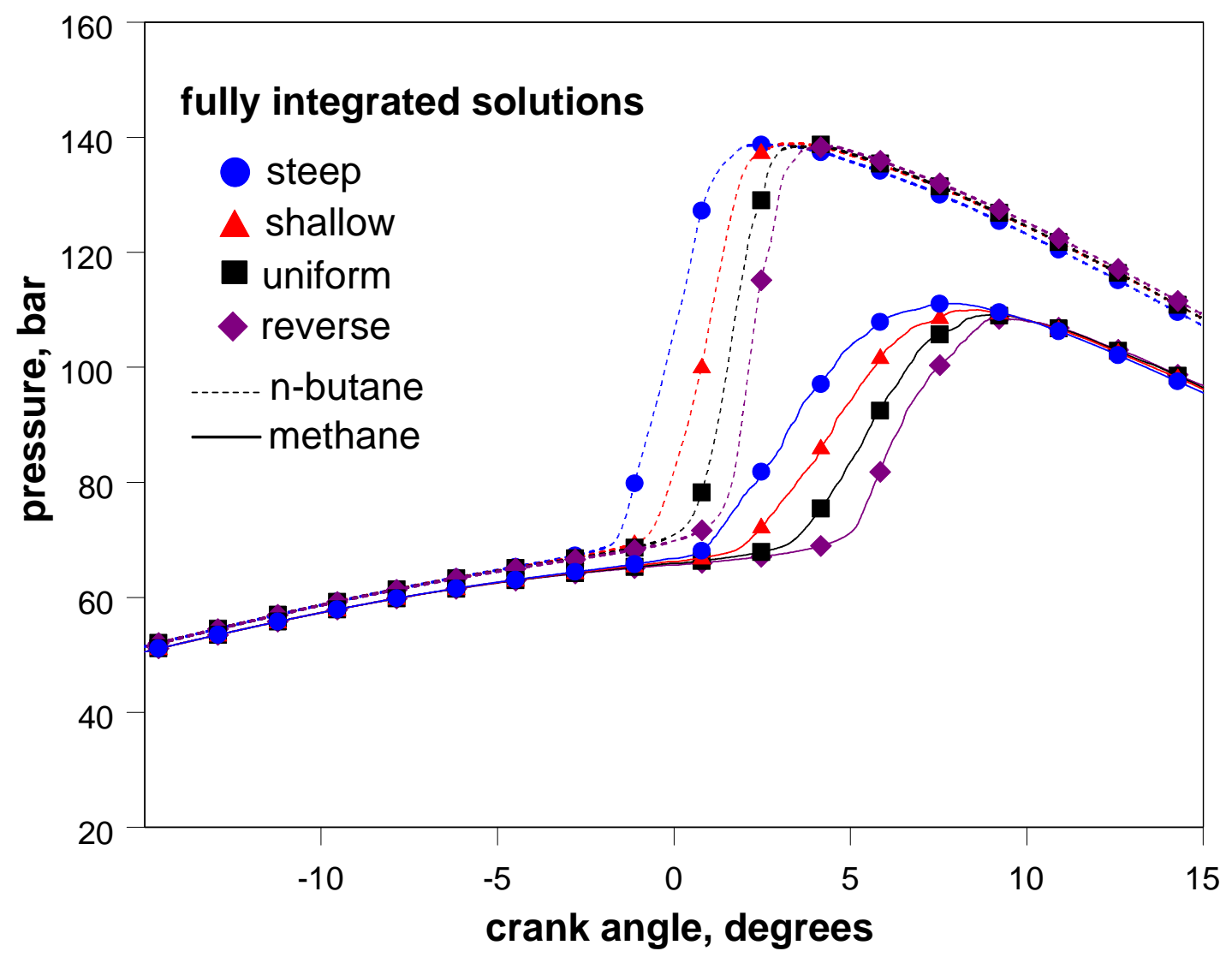

Figure 9. Pressure as a function of crank angle for the fully integrated fluid mechanicschemical kinetics calculations, for methane and n-butane, for the four initial equivalence ratio distributions (steep, shallow, homogeneous and reverse). 


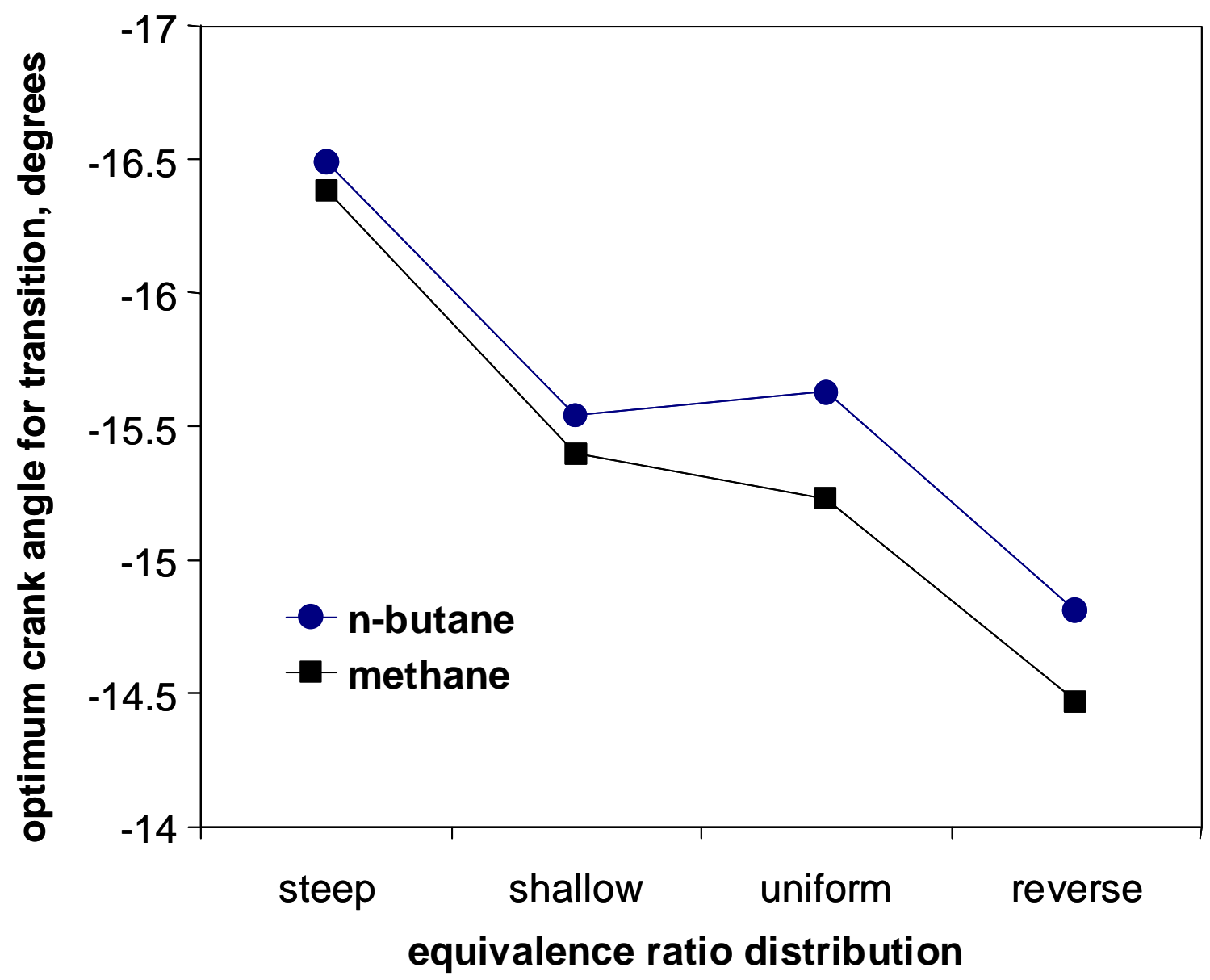

Figure 10. Optimum transition angle that can be used for matching the ignition timing with the multi-zone model, for methane and n-butane, for the four fuel-air distributions. 


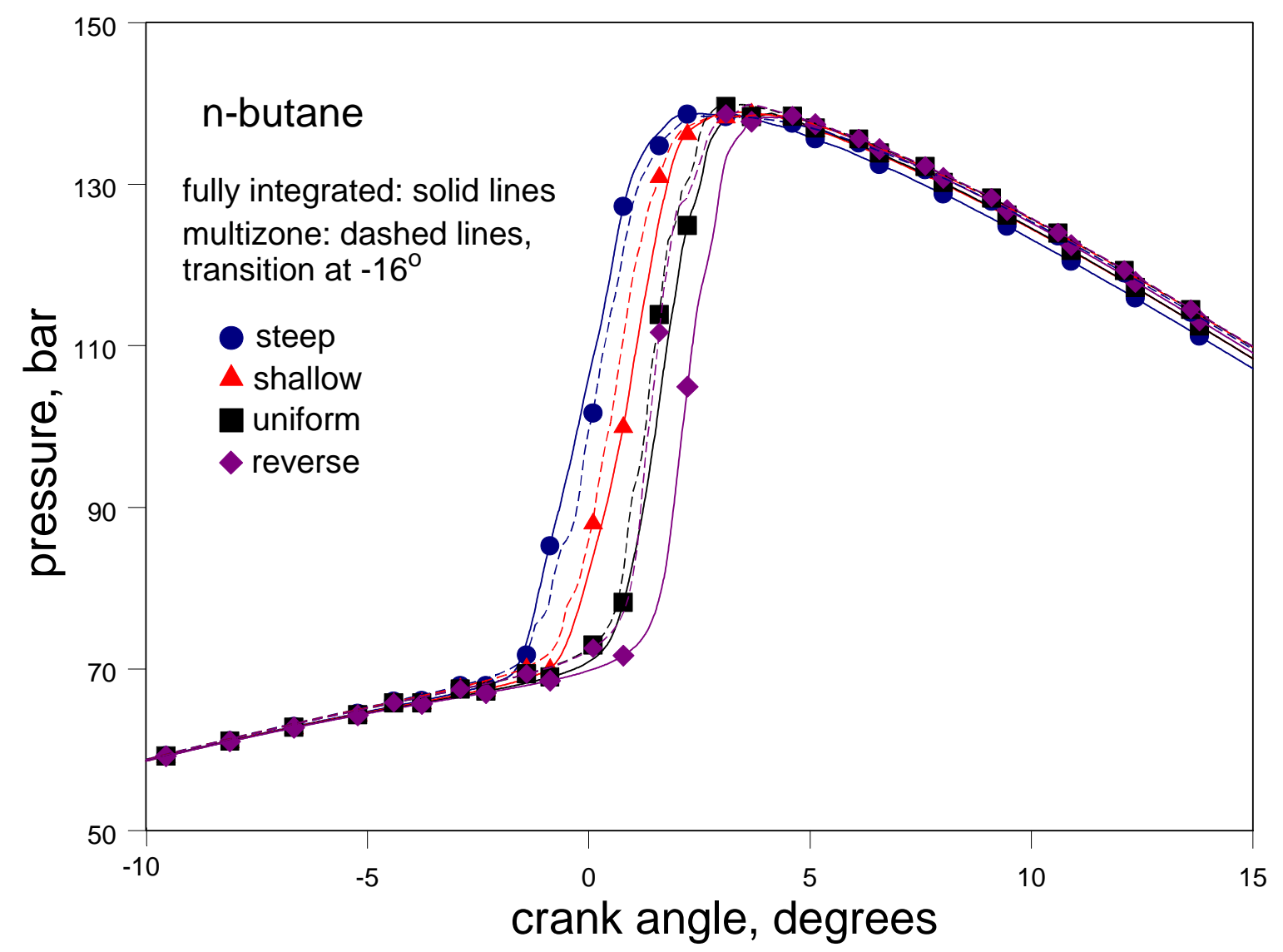

Figure 11. Comparison between fully integrated and multi-zone pressure traces for $\mathrm{n}$ butane, for the four equivalence ratio distributions being considered. All the multi-zone solutions shown in the figure consider $-16^{\circ}$ as the transition angle between the fluid mechanics and the chemical kinetic solution. 


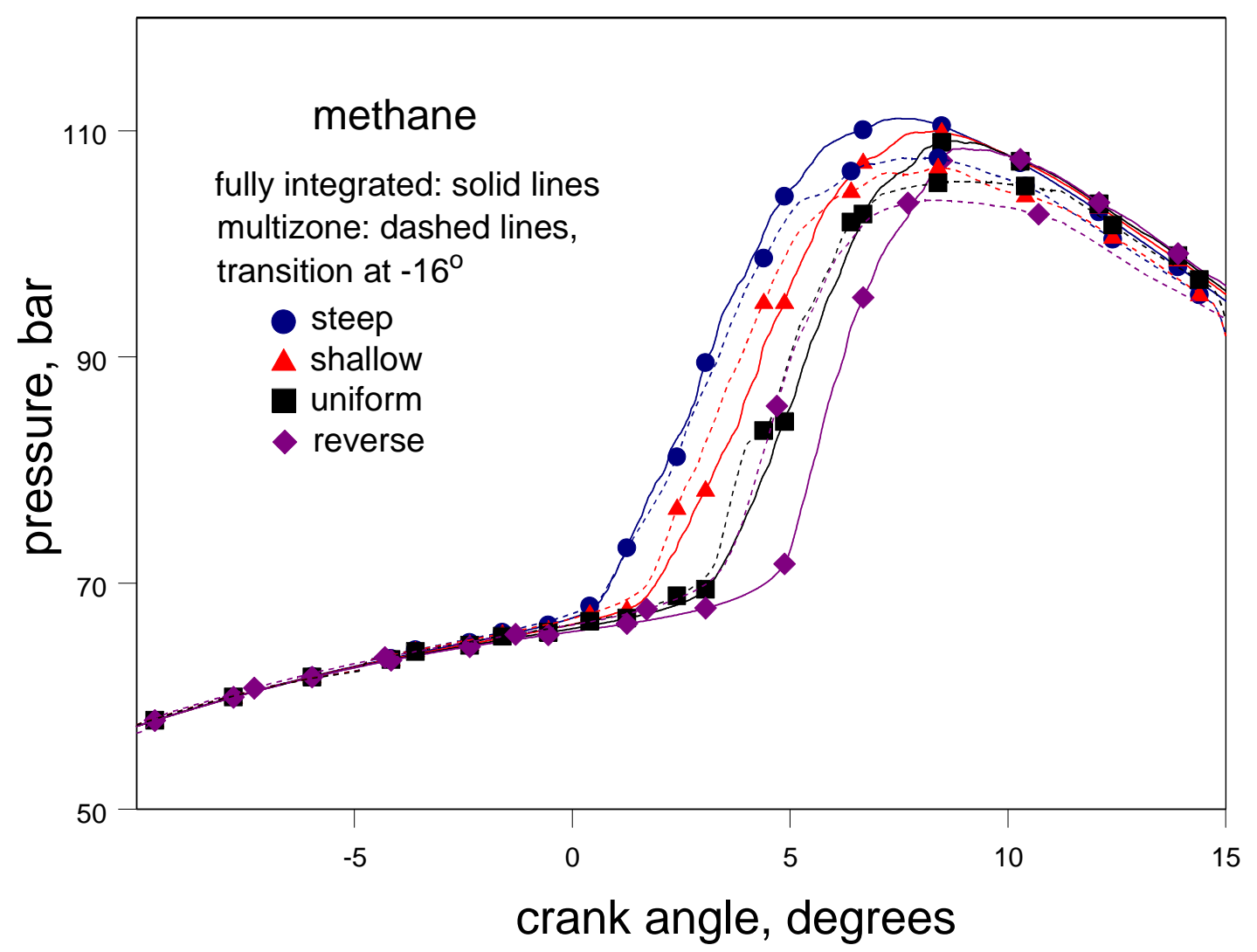

Figure 12. Comparison between fully integrated and multi-zone pressure traces for methane, for the four equivalence ratio distributions being considered. All the multi-zone solutions shown in the figure consider $-16^{\circ}$ as the transition angle between the fluid mechanics and the chemical kinetic solution. 


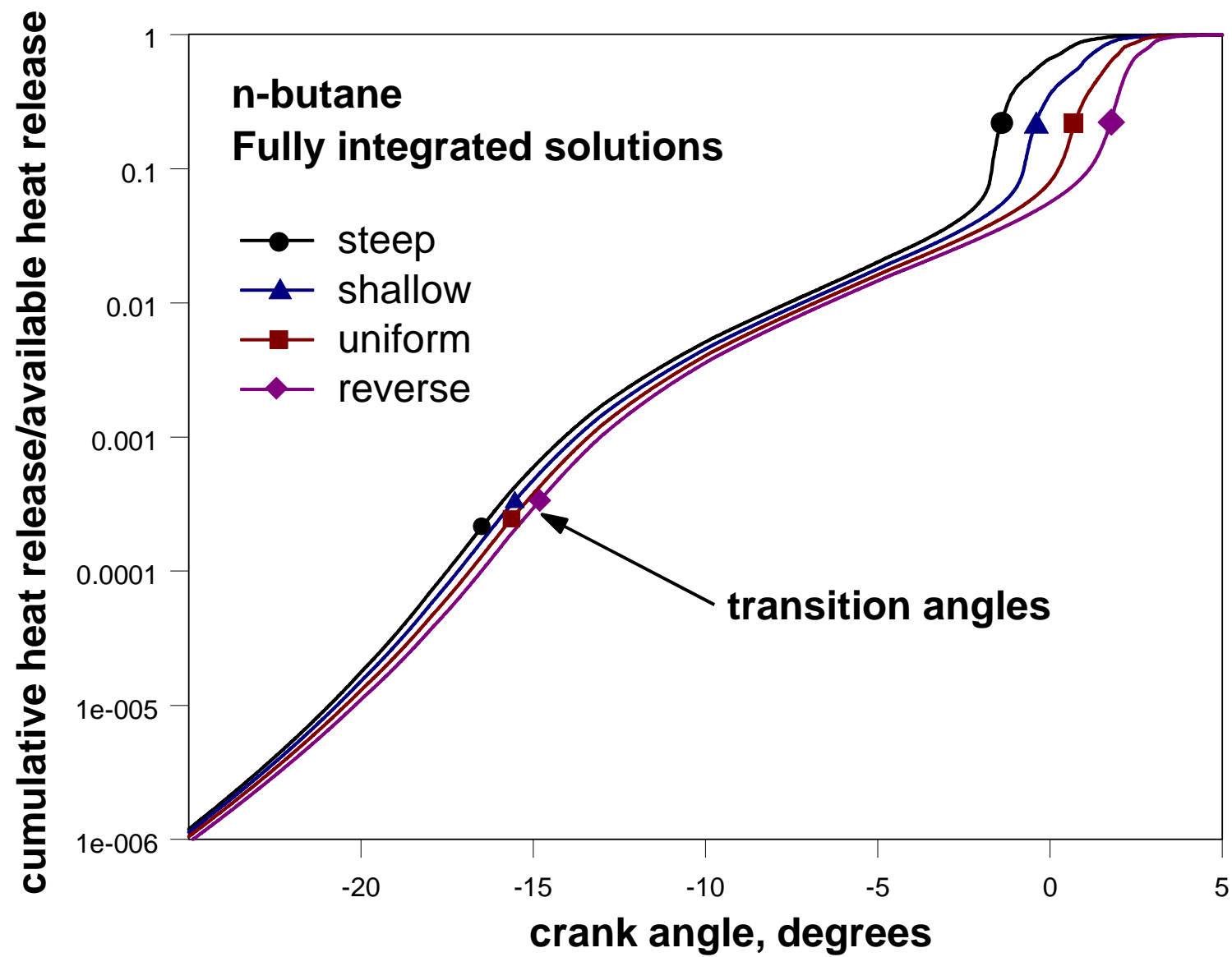

Figure 13. Cumulative chemical heat release, expressed as a fraction of the total available chemical heat release (in logarithmic scale) as a function of crank angle, for the four fuelair distributions, for n-butane fuel. The figure also includes four points that indicate the transition angle that best predicts ignition for the multi-zone model (from Figure 10). 


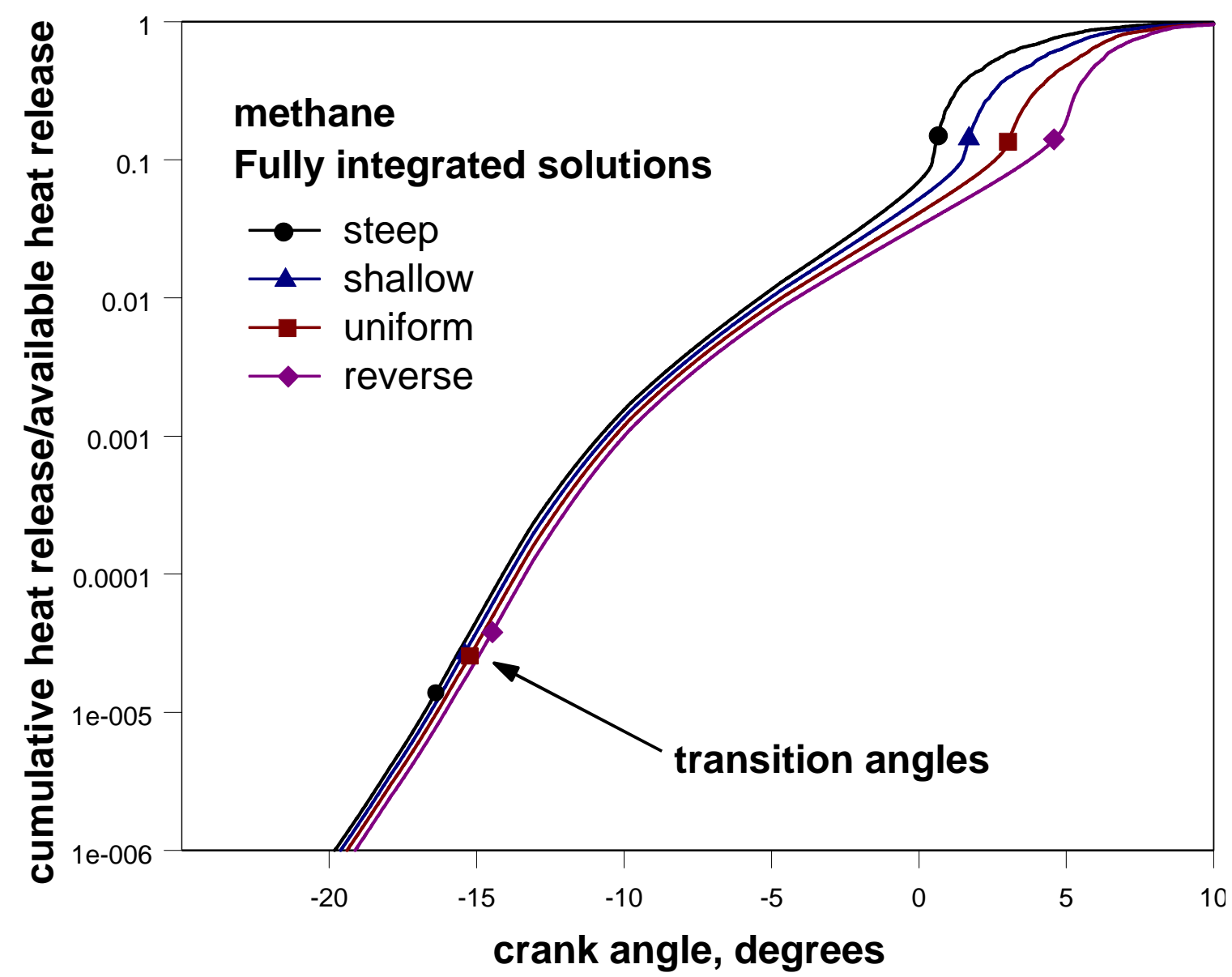

Figure 14. Cumulative chemical heat release, expressed as a fraction of the total available chemical heat release (in logarithmic scale) as a function of crank angle, for the four fuelair distributions, for methane fuel. The figure also includes four points that indicate the transition angle that best predicts ignition for the multi-zone model (from Figure 10). 


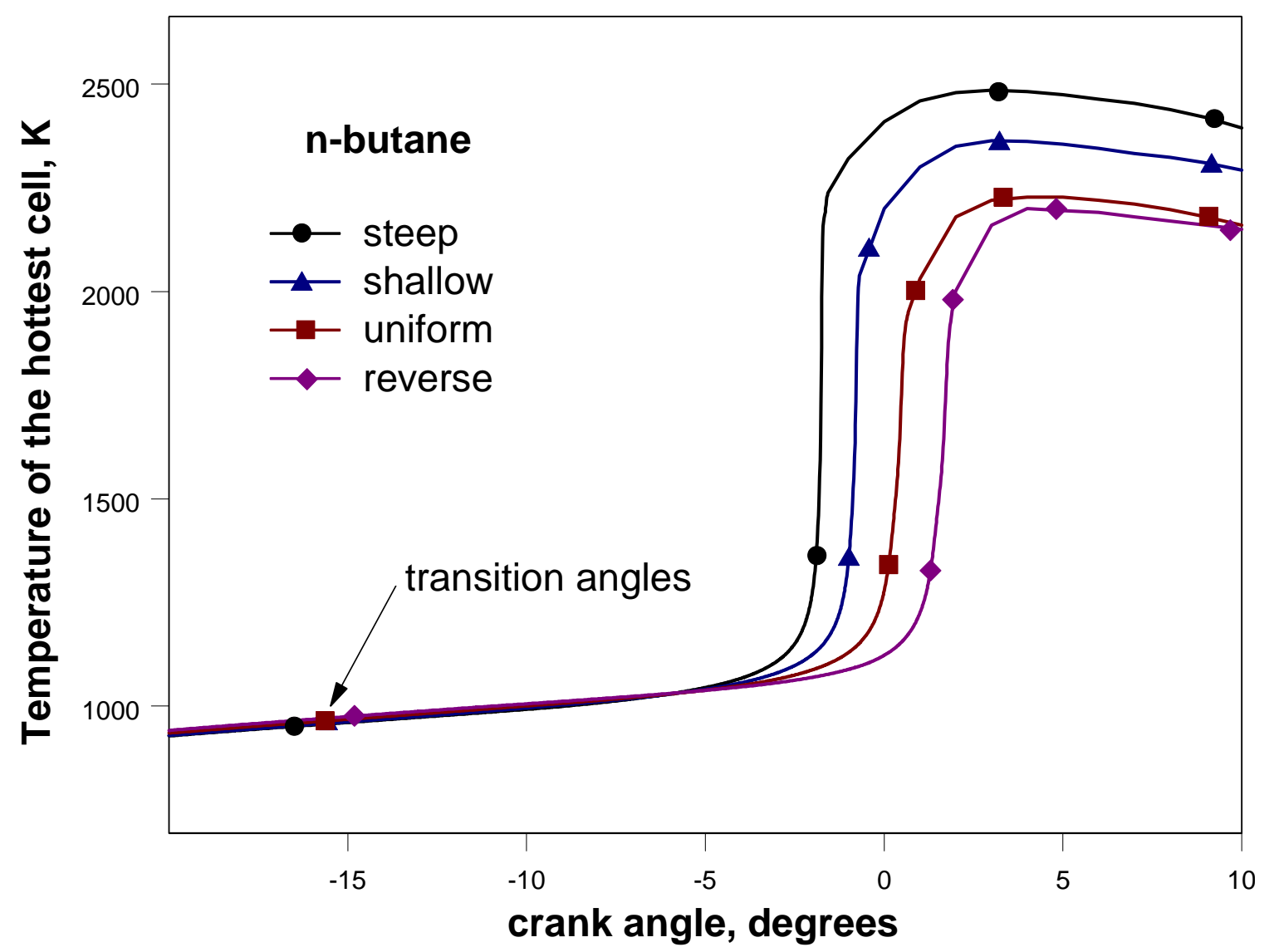

Figure 15. Temperature of the hottest cell as a function of crank angle, for the four fuelair distributions, for n-butane fuel. The temperature distributions are obtained from the fully integrated runs. The figure also includes four points that indicate the transition angle that best predicts ignition for the multi-zone model (from Figure 10). 


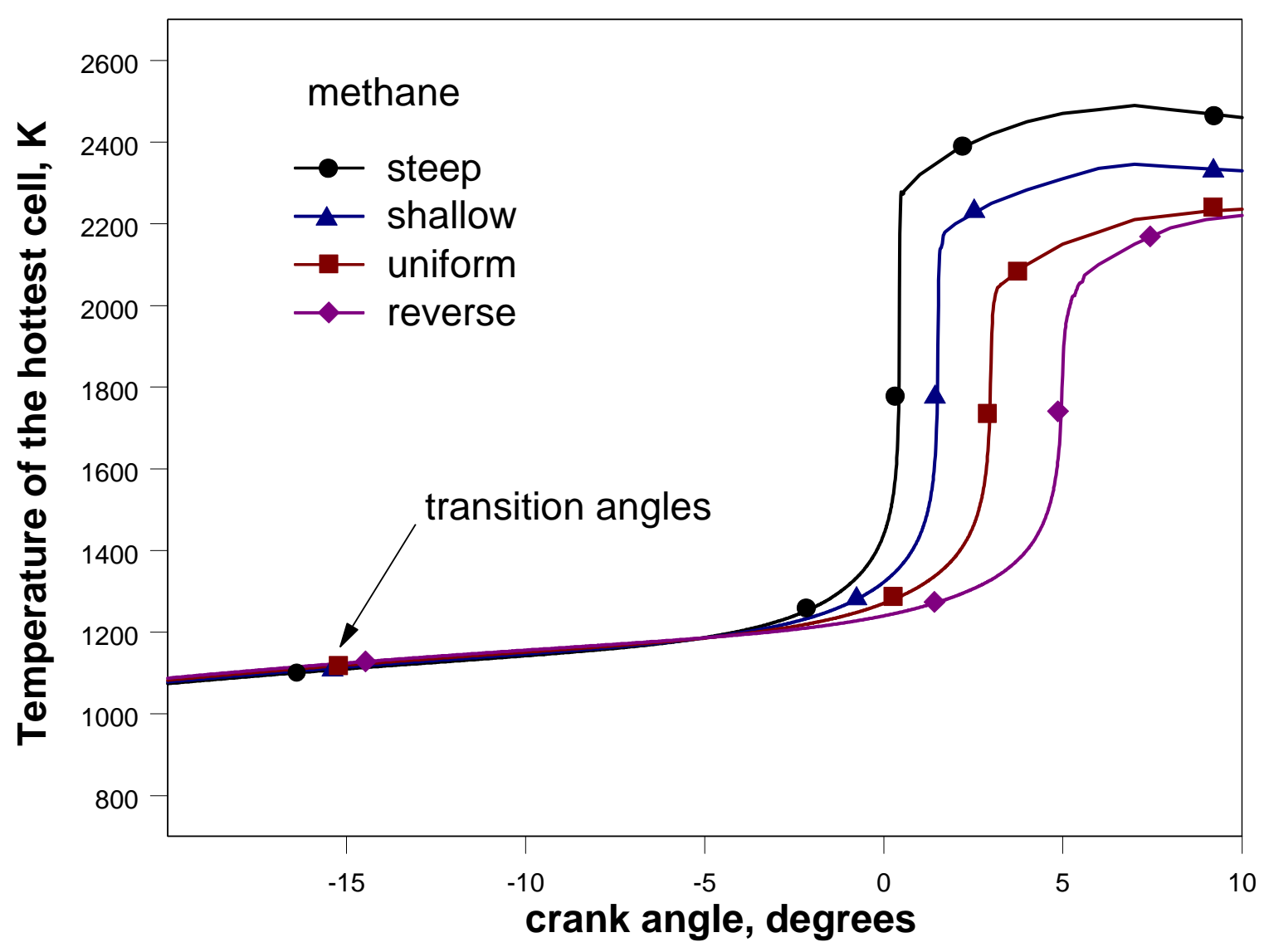

Figure 16. Temperature of the hottest cell as a function of crank angle, for the four fuelair distributions, for methane fuel. The temperature distributions are obtained from the fully integrated runs. The figure also includes four points that indicate the transition angle that best predicts ignition for the multi-zone model (from Figure 10). 